\title{
Interaction between Humic Substances and Metallic Ions: a Selectivity Study of Humic Substances and their Possible Therapeutic Application
}

\section{Ademir dos Santos, ${ }^{*}$, Wander Gustavo Botero, ${ }^{a}$ Iramaia Corrêa Bellin, ${ }^{a}$ Luciana Camargo de Oliveira, ${ }^{a}$ Julio Cesar Rocha, ${ }^{a}$ André Gustavo Ribeiro Mendonça ${ }^{a}$ and Antonio Francisco Godinho ${ }^{b}$}

\author{
${ }^{a}$ Instituto de Química, Universidade Estadual de São Paulo, CP 355, 14801-970 Araraquara-SP, Brazil \\ ${ }^{b}$ Centro de Assistência Toxicológica, Instituto de Biociências, Universidade Estadual de \\ São Paulo, CP 520, 18618-000 Botucatu-SP, Brazil
}

\begin{abstract}
A capacidade de complexação de substâncias húmicas extraídas de amostras de turfa coletadas na região do Rio Mogi em Ribeirão Preto, SP, Brasil, foi determinada utilizando $\mathrm{Al}(\mathrm{III}), \mathrm{Pb}(\mathrm{II}), \mathrm{Cr}(\mathrm{VI})$ e $\mathrm{Cd}(\mathrm{II})$. A seguinte ordem de afinidade foi observada: $\mathrm{Cr}(\mathrm{VI})<$ $\mathrm{Cd}(\mathrm{II})<\mathrm{Pb}$ (II) $<\mathrm{Al}$ (III). O teste toxicológico $\mathrm{LD}_{50}$ mostrou que as substâncias húmicas não são tóxicas até a concentração máxima de $512 \mathrm{mg} \mathrm{kg}^{-1}$. Esses resultados reforçam a possibilidade do uso das substâncias húmicas como agente desintoxicante de metais.
\end{abstract}

The complexation capacity of humic substances extracted from peat samples taken from the Mogi River in Ribeirao Preto, SP, Brazil, was determined using metal ions ( $\mathrm{Al}(\mathrm{III}), \mathrm{Pb}(\mathrm{II})$, $\mathrm{Cr}(\mathrm{VI})$ and $\mathrm{Cd}(\mathrm{II})$ ), yielding the following order of affinity: $\mathrm{Cr}(\mathrm{VI})<\mathrm{Cd}(\mathrm{II})<\mathrm{Pb}$ (II) $<\mathrm{Al}$ (III). An oral $\mathrm{LD}_{50}$ test showed that these humic substances are nontoxic up to a maximum concentration of $512 \mathrm{mg} \mathrm{kg}^{-1}$. These findings reinforce the possibility of using humic substances as a metal detoxicant.

Keywords: humic substance, metals, potentially toxic metals, toxicology

\section{Introduction}

The environmental contamination level by toxic metals has increased as a result of the industrial and populational growth and the poor control of emissions. The Brazilian Association of Companies for the Treatment, Recovery and Disposal of Special Wastes (ABETRE) estimates that of the 2.9 million tons of hazardous industrial wastes generated annually in Brazil, only 600 thousand tons are adequately treated. The $78 \%$ remaining wastes are incorrectly deposited in landfills without any kind of treatment. The news media has reported the contamination of adults, children, empty lots and homes by heavy metals, especially by lead and mercury.

Severe poisoning cases have been reported in Bauru and Paulínia, São Paulo state, in São Luis, Maranhão state and in Santo Amaro da Purificação, Bahia state. ${ }^{1}$ Literature also reports acute poisonings by ingestion, accidentally or otherwise, of compounds used in wood preservation containing chromium, copper and arsenic. ${ }^{2}$ However, the population in general and the government agencies have

*e-mail: ademir@iq.unesp.br no accurate information about the risks of contamination by these metals and the consequences to human health.

About 30 of the elements listed in the periodic table are toxic to humans and animals, especially: lead, aluminum, cadmium and chromium. Poisoning by these metals is more frequent due to their widespread use and hence, their greater release into the environment. Moreover, lead, cadmium and chromium(VI) are not only cumulative and persistent, but are also metals that do not occur naturally in any organism, nor do they play any nutritional or biochemical role in microorganisms, plants or animals. In other words, their presence in living organisms in any concentration is harmful. ${ }^{3}$ Toxic effects of metals have always been considered as acute and evident short-term events, such as the aneuria and bloody diarrhea caused by the ingestion of mercury. Today, medium and long-term occurrences are observed, but the cause-effect relations are little evident and almost always subclinical. These effects are usually difficult to distinguish and have little specificity, for they can be caused by other toxic substances, or by interactions between these chemical agents. Several metallic species are essential to organisms. Many of them, such as sodium(I), calcium(II), potassium(I), 
manganese(II), iron(II), cobalt, molybdenum, chromium (III), copper and zinc, are essential for human health. However, the excessive ingestion of metals, even of the essential ones, may cause irreversible damage to health. ${ }^{4}$

The purpose of any treatment against poisoning by potentially toxic metals is to deactivate them through their fixation by compounds that are little dissociated, i.e., through reactions with chelating agents containing sulphydril groups or compounds that combine these two characteristics. ${ }^{5}$

Since the early 1950s, EDTA has been used as a complexing agent in metal poisoning treatments. However, due to its low selectivity, it also complexes essential metals, making it necessary to replace mineral salts after excretion. The $\alpha$-amino acids have been widely used as chelating agents for this purpose. However, they are very expensive and are only effective in injectable form. ${ }^{6}$ Therefore, the search for low cost, low toxicity, water soluble and selective chelating agents has been the subject of studies in different areas of expertise. ${ }^{7}$

Due to the wide variety and large number of functional groups in humic substances (HS), particularly carboxylic and hydroxylic sites, HS have a highly complexing capacity and relative selectivity. These characteristics are very convenient for HS to act as metallic species complexing agents in poisoning situations. ${ }^{8}$

In this study, an evaluation of the possible use of humic substances as detoxicating agents in acute poisoning by potentially toxic metals was made.

\section{Material and Methods}

\section{Chemicals and reagents}

All reagents used were of high-purity grade unless otherwise stated. Working solutions of acids were prepared by diluting 30\% hydrochloric acid (suprapur, Merck AG) and $65 \%$ nitric acid (p.a. Merck AG, pre purified by sub boiling distillation) with high-purity water (Milli-Q system, Millipore). The same water used for preparing sodium hydroxide solution using monohydrate, $\mathrm{NaOH}_{2} \mathrm{O}$ (suprapur, Merck AG). For calibrations and metal determinations appropriate synthetic standard (ICP multielement standard solution IV, Merck AG) was employed.

\section{Humic substance extraction}

Peat samples were collected in region of the Mogi River in Ribeirao Preto city, Sao Paulo state, Brazil. The humic substances (HS) were extracted following the procedure recommended by the International Humic Substances Society. Chemicals and reagents were used as described previously. ${ }^{9}$ To this end, dried soil samples were ground and sifted through a $2 \mathrm{~mm}$ sieve. 500 grams of the resulting material were extracted with a volume of $0.1 \mathrm{~mol} \mathrm{~L}^{-1} \mathrm{HCl}$ solution equal to ten times the sample's weight. The solution $\mathrm{pH}$ was adjusted between 1.0 and 2.0 with $1.0 \mathrm{~mol} \mathrm{~L}^{-1} \mathrm{HCl}$ solution. The peat/HCl mixture was shaken for $1 \mathrm{~h}$ and the suspension was allowed to settle. The mixture was then centrifuged at $1478 \mathrm{~g}$ for $10 \mathrm{~min}$ and the supernatant separated from the sediment. The sediment was neutralized with 1.0 mol L-1 NaOH solution to $\mathrm{pH} 7.0$ and a volume of $0.1 \mathrm{~mol} \mathrm{~L}^{-1}$ $\mathrm{NaOH}$ solution equal to ten times the sample's weight was added under a nitrogen atmosphere. This mixture was shaken for $4 \mathrm{~h}$ and then allowed to settle overnight, after which the supernatant was separated from the sediment by centrifugation at $1478 \mathrm{~g}$ for $10 \mathrm{~min}$ and the sediment discarded.

\section{Purification of the humic substances}

Humic substances extracted from peat samples were transferred into dialysis tubes and dialyzed against water in order to eliminate soluble salts. The external water was replaced three times after 3-5 h and then every $12 \mathrm{~h}$ until no $\mathrm{Cl}^{-}$could be detected. Subsequently, the HS were evaporated in vacuum and oven-dried at $55^{\circ} \mathrm{C}$ in circulating air.

\section{Humic substance characterization}

\section{Elemental analysis}

The elementary composition (C, H, O, N and S) was determined using a Thermo Finnigan Flash EA 1112 elementary analyzer.

\section{Infrared spectroscopy}

The spectra in the infrared region of the HS extracted from peat sample were obtained using $\mathrm{KBr}$ pellets in a Nicolet 730 SX-FT spectrometer. ${ }^{10}$

\section{Differential thermal analysis and thermogravimetric analysis}

For the differential thermal analysis (DTA) and for the thermogravimetric analysis (TG), approximately $8 \mathrm{mg}$ of HS extracted from peat sample was continually heated from 40 to $1000{ }^{\circ} \mathrm{C}$, at a heating rate of $10^{\circ} \mathrm{C} \mathrm{min}$, in a synthetic air atmosphere $\left(100 \mathrm{~mL} \mathrm{~min}^{-1}\right)$ and an alumina crucible. The DTA and TG curves were simultaneously obtained, using a TA Instruments SDT-2960 device. ${ }^{11}$

\section{Electron Paramagnetic Resonance (EPR)}

The EPR spectra were acquired in a Bruker EMXbrand spectrometer operating in the $\mathrm{X}$ band $(\sim 9 \mathrm{GHz})$ at ambient temperature. For quantitative analysis, quartz 
tubes were filled with the HS samples, noting down their respective masses for later data normalization To obtain the areas of the signals, the $I x\left(\Delta H_{P P}\right)^{2}$ approximation was used, in which $I$ is the signal intensity and $\Delta H_{P P}$ is the width of the signal taken peak to peak. The semiquinone-type free radical was quantified by the standard secondary method, ${ }^{12}$ using a ruby crystal $\left(\mathrm{Al}_{2} \mathrm{O}_{3}\right)$ containing $0.5 \%$ of $\mathrm{Cr}$ (III) per weight. Its g factor is 1.263 , so it does not interfere with the semiquinone free radical, whose $\mathrm{g}$ value lies at around 2.003. ${ }^{13}$

Potentially toxic metal (PTM) complexation and HS selectivity study with a-amino acids

The complexing capacity of potentially toxic metals (PTM) with humic substances (HS) was determined and compared with $\alpha$-amino acids using an ultrafiltration system (Figure 1), which proved to be useful for analytical purposes such as protein separation and the determination of stability constants. ${ }^{14}$ This procedure prevents the large molecular size HS and their complexes from passing through the flat ultrafiltration membrane (Gelman PallFiltron OMEGA, cut-off $1 \mathrm{kDa}$ ), while the amino acids and free metal ions pass through the membrane freely.

$40 \mathrm{~mL}$ of HS solution $\left(0.5 \mathrm{mg} \mathrm{mL}^{-1}\right)$ and $10 \mathrm{~mL}$ of multielement standard solution $\left(20 \mathrm{mg} \mathrm{L}^{-1}\right.$ of $\mathrm{Al}, \mathrm{Cu}, \mathrm{Pb}$, $\mathrm{Mn}, \mathrm{Zn}, \mathrm{Cd}$ and $\mathrm{Ni}$ ) were previously prepared and mixed together. $\mathrm{pH}$ was then adjusted to 5.0 with $0.1 \mathrm{~mol} \mathrm{~L}^{-1}$ $\mathrm{NaOH}$ solution, water was added up to a final volume of $190 \mathrm{~mL}$ and the resulting mixture shaken for $24 \mathrm{~h}$ in order to attain equilibrium. The mixture circulated through the system and a small volume $(\cong 2.0 \mathrm{~mL}$ ) was removed after filtration in order to set the zero time. This sample contained free metal ions that had not been retained by HS. $10 \mathrm{~mL}$ of the solution containing amino acids $(3.0$ mmol L'-1) was then added to the circulating mixture and, at various intervals of time $(5,10,20,30,60120,180$, 240, 360, 720 and $1440 \mathrm{~min}$ ), filtrates were removed and the metal ion concentration determined.

\section{Competition between potentially toxic metals and humic substances enriched with major essential metals}

Based on the HS complexing capacity, $10 \mathrm{~mL}$ of standard multielement solution of major essential metals $\left(20 \mathrm{mg} \mathrm{L}^{-1}\right.$ $\mathrm{Ca}$ (II) and $\mathrm{Mg}$ (II)) were added to $40 \mathrm{~mL}$ of $0.50 \mathrm{mg} \mathrm{mL}^{-1} \mathrm{HS}$ solution, $\mathrm{pH}$ was adjusted to 5.0 with a $\mathrm{NaOH}$ solution of 0.1 mol L-1, water was added up to a volume of $190 \mathrm{~mL}$ and the mixture shaken for $24 \mathrm{~h}$ at room temperature (about $28^{\circ} \mathrm{C}$ ). The tangential ultrafiltration system described in the previous item and equipped with a $1 \mathrm{kDa}$ membrane was used. Before

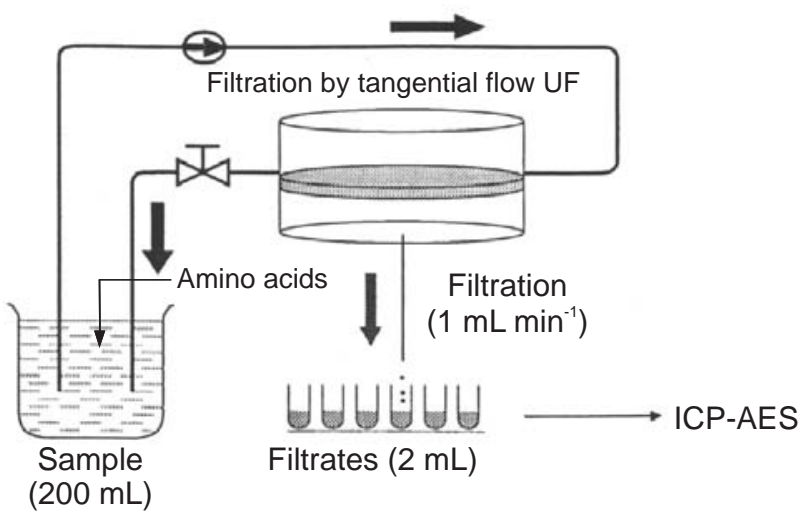

Figure 1. Analytical approach used to determinate the complexing capacity of humic substances by potentially toxic metals and study the selectivity between humic substances and $\alpha$-amino acids.

adding the potentially toxic metal solution of ( $\mathrm{Al}(\mathrm{III}), \mathrm{Pb}(\mathrm{II})$, $\mathrm{Cd}(\mathrm{II})$ or $\mathrm{Cr}(\mathrm{VI}))$, the system was pumped for about $5 \mathrm{~min}$ to condition the membrane. The first aliquot (about $2 \mathrm{~mL}$ ) was then filtered, corresponding to zero time, i.e., before the addition of the potentially toxic metal solution. This aliquot contained a small amount of metals corresponding to the free fraction (not complexed with HS), plus the fraction bound to the HS with a molecular size of less than $1 \mathrm{kDa}$. Aliquots of potentially toxic metal solution were added to the solution of HS-major essential metals to final concentrations of $0.25,0.50$, 1.00, 2.00, 5.00, 10.00 and $20.00 \mathrm{mg} \mathrm{L}^{-1}$. After each addition, the mixture was shaken for $30 \mathrm{~min}$ to reach the exchange equilibrium. Aliquots of about $2 \mathrm{~mL}$ were removed and the concentrations of free metal species were determined by inductively coupled plasma-atomic emission spectrometry atomic emission spectrometry coupled to induced argon plasma-ICP-OES using for this purpose, a Thermo Jarrel AshCID-DUO Spectrometer, according to the experimental conditions given in Table 1.

\section{$D L_{50}$ toxicological test}

The oral $\mathrm{LD}_{50}$ was determined using five adult male Wistar rats (weight 180-220 g) per dose level, with nine successive dose levels being tested and with the values

Table 1. Operating parameters for the ICP-OES determinations

\begin{tabular}{ll}
\hline Operating parameters & \\
\hline Incident power & $1.5 \mathrm{~kW}$ \\
Plasma air flow-rate & $15 \mathrm{~L} \mathrm{~min}^{-1}$ \\
Nebulizer air flow-rate & $1.2 \mathrm{~L} \mathrm{~min}^{-1}$ \\
Auxiliary air flow-rate & $0.5 \mathrm{~L} \mathrm{~min}^{-1}$ \\
Sample flow-rate & $2.4 \mathrm{~mL} \mathrm{~min}^{-1}$ \\
& $\mathrm{Al} 309271\{084\}$ \\
Analytical lines & $\mathrm{Pb} 220353\{117\}$ \\
& $\mathrm{Cd} 226502\{115\}$ \\
& $\mathrm{Cr} 283563\{092\}$
\end{tabular}


between successive dose levels differing by the constant two. Three separate experiments were conducted to evaluate humic substance lethality. Tested doses ranged from $2 \mathrm{mg} \mathrm{kg}^{-1}$ to $512 \mathrm{mg} \mathrm{kg}^{-1}$. The animals were kept under observation for a 72 hours period to determine possible mortality. After this period, the animals were euthanized with an overdose of anesthetic ether and their organs were examined macroscopically. ${ }^{15}$

\section{Results and Discussion}

\section{Elemental analysis}

Elemental analysis is a technique that has been employed to characterize humic substances. According to Rocha et al., ${ }^{16}$ the results of elemental compositions provide information about the structural characteristics, molecular formula, purity, geochemistry and diagenesis of humic substances.

The atomic ratios of $\mathrm{H} / \mathrm{C}$ and $\mathrm{C} / \mathrm{N}$ provide indications about structure and molecular formula of humic substances. ${ }^{17}$ The hydrogen content is related to the saturation degree. In other words, an increase in the hydrogen content indicates a greater number of aliphatic carbons $\left(\mathrm{CH}_{2}\right)$ than of insaturated ones $(\mathrm{C}=\mathrm{C}) .{ }^{18}$ The value obtained for the atomic ratio $\mathrm{H} / \mathrm{C}$ is close to those reported in the literature for similar studies (Table 2).

$\mathrm{C} / \mathrm{O}$ atomic ratio is related to the carbohydrate content in humic substances. High values of this ratio indicate a greater degree of humification caused by a decrease in carbohydrate content. In comparison with the literature (Table 2), note that the sample under study contained a greater number of oxygenated groups, indicating a lower degree of humification.

\section{Infrared spectroscopy}

The spectrum in the infrared region of humic substances extracted from peat samples was characteristic when compared with spectra of different samples reported in the literature. ${ }^{22,23}$ The most important characteristics of the spectrum are: a wide band at around $3400 \mathrm{~cm}^{-1}$ due to $\mathrm{OH}$ stretching of various groups such as phenols and

Table 2. Atomic ratios $(\mathrm{H} / \mathrm{C}, \mathrm{C} / \mathrm{N}$ and $\mathrm{C} / \mathrm{O})$ in different samples extracted from peat originating from different regions, according to the literature

\begin{tabular}{lccl}
\hline Samples & & \multicolumn{2}{l}{ References } \\
& H/C & C/O & \\
\hline Humic acid from peat & 1.1 & 1.92 & Li et al., $2003^{19}$ \\
Humic acid from peat & 1.38 & 1.14 & Guignard et al., 2000 \\
Humic substance from peat & 1.94 & nd & Rosa et al., 1999 \\
The present study & 1.16 & 0.81 & 2007 \\
\hline
\end{tabular}

alcohols; two peaks at $2920 \mathrm{~cm}^{-1}$ and $2846 \mathrm{~cm}^{-1}$ caused by $\mathrm{C}-\mathrm{H}$ stretching of aliphatic carbon; a band in the region of $1715 \mathrm{~cm}^{-1}$ corresponding to $\mathrm{C}=\mathrm{O}$ stretching of ketones and/or carboxylic groups; a peak at $1616 \mathrm{~cm}^{-1}$ attributed to $\mathrm{C}=\mathrm{C}$ stretching of an aromatic element and a strong peak at $1020 \mathrm{~cm}^{-1}$ ascribed to $\mathrm{Si}-\mathrm{O}$ stretching. ${ }^{24}$

\section{Differential thermal analysis and thermogravimetric analysis}

Literature offers little data about the thermal behavior of humic substances extracted from peat samples. Figure 2 shows the DTA and TG curves for peat HS.

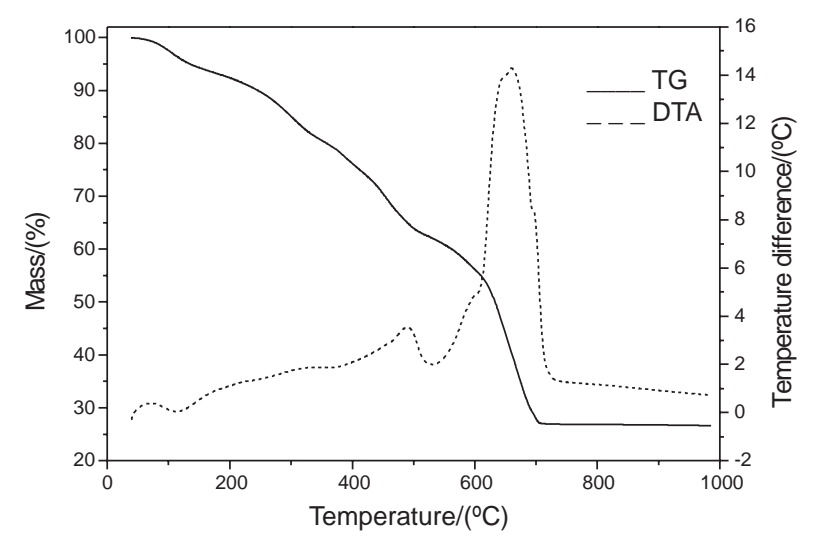

Figure 2. Thermogravimetric analysis (TG) and differential thermal analysis (DTA) curves of humic substances extracted from peat sample.

Figure 2 shows an endothermic peak close to $100^{\circ} \mathrm{C}$ on the DTA curve, accompanied by a loss of mass on the TG curve, which corresponds to the sample's dehydration. A continuous mass loss was characterized in the interval of 200 to $700^{\circ} \mathrm{C}$ on the TG curve, with two exothermic peaks showing maxima at $460^{\circ} \mathrm{C}$ and $660^{\circ} \mathrm{C}$ on the DTA curve, which correspond to the thermal decomposition of the organic matter. According to Leinweber \& Schulten, ${ }^{25}$ the thermal decomposition of phenolic compounds and lignin monomers of organic matter occurs at around 300 to $400^{\circ} \mathrm{C}$; however, alkylaromatics and lignin dimers degrade at temperatures of 500 to $600^{\circ} \mathrm{C}$. Sheppard \& Forgeron $^{26}$ found that the thermal degradation of carbohydrates occurs at temperatures exceeding $350^{\circ} \mathrm{C}$.

\section{Electron paramagnetic resonance (EPR)}

Our findings on the spin concentration of the HS

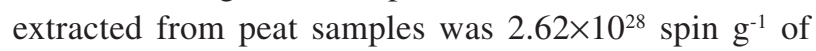
carbon, with a higher degree of humification than the values reported by Hayes, ${ }^{27}$ but comparable to the values reported for more humified samples, ${ }^{28}$ indicating a high degree of humification of the humic substances under study and corroborating the data obtained from our elemental analysis. 
Capacity of HS to complex potentially toxic metals

In titration with metallic ions, saturation of the strongest binding sites occurs first, followed by saturation of the weaker ones. Figure 3 is typical of the titration of humic substances extracted from peat samples with a standard solution of potentially toxic metals, $\mathrm{Al}$ (III) for instance, using the tangential flow ultrafiltration procedure. The complexing capacity (CC) was determined, by both methods, by plotting the concentration of free metal (mmol $\left.\mathrm{L}^{-1}\right)$ as a function of the total metal concentration $\left(\mathrm{mmol} \mathrm{L}^{-1}\right)$. The curve indicates a change in slope in the final portion and the complexing capacity was obtained by the intersection of the two linear sections. ${ }^{29-32}$

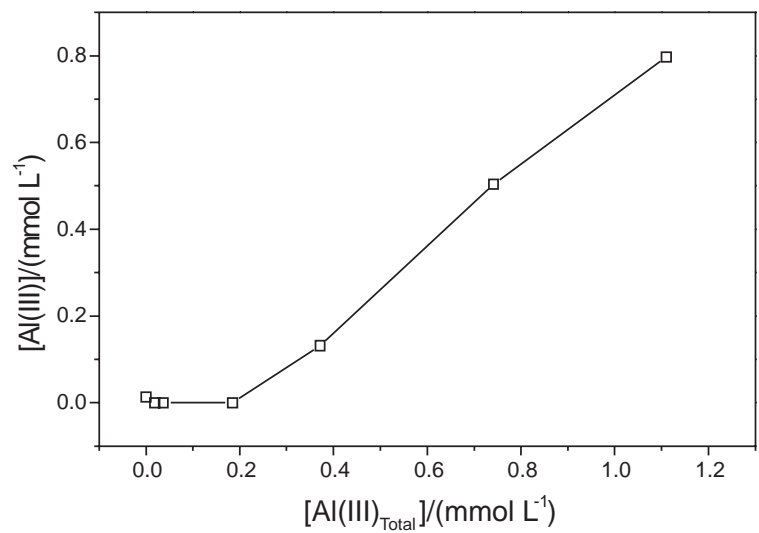

Figure 3. Complexing capacity curve of humic substances extracted from peat sample by $\mathrm{Al}(\mathrm{III})$, using the tangential ultrafiltration technique. Conditions: concentration of the samples: $100 \mathrm{mg} \mathrm{L}^{-1} ; \mathrm{pH} 5.0 ; I=0.10 \mathrm{~mol}$ $\mathrm{L}^{-1} \mathrm{NaNO}_{3}$

Table 3 shows the complexing capacity of the humic substances extracted from peat samples by the potentially toxic metals.

Table 3. Complexing capacity of humic substances extracted from peat sample by the potentially toxic metals $\mathrm{Al}(\mathrm{III}), \mathrm{Pb}(\mathrm{II}), \mathrm{Cr}(\mathrm{VI})$ and $\mathrm{Cd}(\mathrm{II})$

\begin{tabular}{lc}
\hline Metals & Complexing capacity $\left(\mathrm{mmol} \mathrm{metal} \mathrm{g}{ }^{-1} \mathrm{COT}\right)$ \\
\hline $\mathrm{Al}(\mathrm{III})$ & $13.59 \pm 0.17$ \\
$\mathrm{~Pb}(\mathrm{II})$ & $8.33 \pm 0.13$ \\
$\mathrm{Cd}(\mathrm{II})$ & $4.85 \pm 0.08$ \\
$\mathrm{Cr}(\mathrm{VI})$ & $4.63 \pm 0.06$ \\
\hline
\end{tabular}

Based on the complexing capacity results shown in Table 3, note the following increasing order of affinity of the metallic ions for the complexing sites of the humic macromolecules:

$$
\mathrm{Cr}(\mathrm{VI})<\mathrm{Cd}(\mathrm{II})<\mathrm{Pb}(\mathrm{II})<\mathrm{Al}(\mathrm{III})
$$

This order can be explained by the classification of "hard" and "soft" acids and bases. According to
Pearson, ${ }^{33}$ chemical species can be classified as "hard" and "soft" acids and bases and this concept of hardness and softness helps interpret a large part of the complexation phenomena. The tendency of "soft" acids to bind to "soft" bases and of "hard" acids to bind to "hard" bases explains how the elements are found on the earth's crust. According to this classification, there are two main classes: the lithophylic elements and the calcophylic elements. Lithophylic elements are hard cations, which include $\mathrm{Al}(\mathrm{III}), \mathrm{Li}(\mathrm{I}), \mathrm{Mg}(\mathrm{II})$ and $\mathrm{Ti}(\mathrm{II})$, and are found in association with hard $\mathrm{O}^{-2}$ base. On the other hand, calcophylic elements are often found in combination with sulfide minerals and include $\mathrm{Cd}(\mathrm{II})$, $\mathrm{Sb}(\mathrm{III})$ and $\mathrm{Bi}(\mathrm{III})$. This corroborates the results reported here, evidencing the greater complexing capacity of humic substances by the $\mathrm{Al}$ ion, because they have high contents of oxygenated, an intermediary complexing capacity by the $\mathrm{Pb}$ ion and a low complexing capacity by the $\mathrm{Cd}$ and $\mathrm{Cr}$ ions.

\section{Selectivity study between humic substances and $\alpha$-amino acids}

As described by Santos et al., ${ }^{34}$ in a previous short report and in accordance with those results, the following orders of metal ions retained by HS in contrast to different amino acids have been established: $(i)$ methionine: $\mathrm{Al}(\mathrm{III})>\mathrm{Pb}(\mathrm{II})>$ $\mathrm{Cu}(\mathrm{III})>\mathrm{Cd}(\mathrm{II})>\mathrm{Ni}(\mathrm{II})>\mathrm{Mn}(\mathrm{II})>\mathrm{Zn}$ (II); (ii) methionine sulfoxide: $\mathrm{Al}($ III) $>\mathrm{Pb}$ (II) $>\mathrm{Cu}$ (III) $>\mathrm{Ni}$ (II) $>\mathrm{Cd}$ (II) $>\mathrm{Zn}$ (II) $>$ $\mathrm{Mn}(\mathrm{II})$; and (iii) cysteine: $\mathrm{Al}(\mathrm{III})>\mathrm{Pb}(\mathrm{II})>\mathrm{Cu}(\mathrm{III})>\mathrm{Ni}(\mathrm{II})>$ $\mathrm{Cd}(\mathrm{II})>\mathrm{Mn}(\mathrm{II})>\mathrm{Zn}$ (II). Moreover, the kinetics of extraction from the HS phase showed similar profiles for three a-amino acids, i.e., slow kinetics for the first group, $\mathrm{Cu}$ (III) and $\mathrm{Pb}$ (II), with reaction times of 5 to $10 \mathrm{~min}$, and a faster interaction in the second group, $\mathrm{Zn}$ (II), $\mathrm{Mn}$ (II), $\mathrm{Cd}(\mathrm{II})$ and $\mathrm{Ni}(\mathrm{II})$, reaching equilibrium in about $60 \mathrm{~min}$. Aluminum(III) binding to HS appeared to be the strongest for all the amino acids studied, since practically no aluminum was detected in the liquid phase. The most powerful complexing agent appeared to be cysteine, most probably owing to the presence of thiol groups.

Competition between potentially toxic metals and humic substances enriched with major essential metals

Figure 4 illustrates the results obtained and the tendencies of exchange of the major essential metals complexed by humic substances extracted from peat samples for the potentially toxic metals $\mathrm{Al}, \mathrm{Pb}, \mathrm{Cd}$ and $\mathrm{Cr}$.

According to our data, the major essential metals display a similar behavior and are released when potentially toxic metals are complexed by HS. We can thus infer that the release of essential metals occurs after 


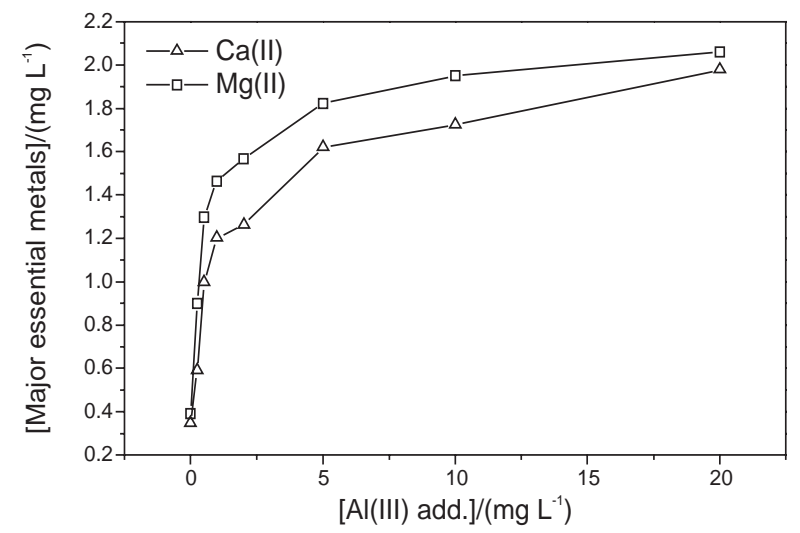

Figure 4. Tendencies for exchange of the major essential metals complexed by humic substances extracted from peat samples for the potentially toxic metals $\mathrm{Al}(\mathrm{III}), \mathrm{Pb}(\mathrm{II}), \mathrm{Cd}(\mathrm{II})$ and $\mathrm{Cr}(\mathrm{VI})$.

occupation of the complexation sites by potentially toxic metals (PTM), when their affinity is greater than that of the essential metals.

The metal ion showing the greatest lability was $\mathrm{Mg}(\mathrm{II})$ when exchanged with $\mathrm{Al}$ and $\mathrm{Pb}$, while $\mathrm{Ca}$ proved to be the most labile metal when exchanged with $\mathrm{Cd}$ and $\mathrm{Cr}$. However, generally speaking, practically all the major essential metal ions complexed to the humic substances were changed when in contact with potentially toxic metals (PTM), allowing us to infer that HS-PTM complexes are more stable than HS$\mathrm{Ca}$ and HS-Mg complexes.

Note that, in some cases, there is a higher release of essential metals than the one added, which is due to the occupation of the potentially toxic metals not only by the sites occupied by essential metals in contact for 24 hours, but also by the sites that have metals originally complexed to humic substances.

Looking at the potentially toxic metals as exchangers, we can infer that metal ions with greatest complexing capacities tend to form most stable complexes. When potentially toxic metal ions compete with sites complexed with essential metal ions, they exchange, releasing them.

\section{Toxicological tests}

The oral $\mathrm{LD}_{50}$ of humic substances for rats exceeds $512 \mathrm{mg} \mathrm{kg}^{-1}$. Higher doses than $512 \mathrm{mg} \mathrm{kg}^{-1}$ were not tested due to the impossibility of dissolving large amounts of humic substance in water. No death occurred pursuant to the nine dosage levels tested here. After the animals were euthanized, no alteration was detected by macroscopic examination of their organs. The only alteration observed during the 72 hours period after administration of the humic substances was darker, softer feces.

\section{Conclusions}

Humic substances extracted from peat samples showed high humification degree and great diversity of functional groups being responsible for the complexation with metallic species. The results of this complexation capacity study demonstrated that humic substances have strong affinity for potentially toxic metals, especially for the $\mathrm{Al}(\mathrm{III})$ ion, forming relatively stable complexes.

The increasing order of affinity of humic substances for the potentially toxic metal ions studied here is $\mathrm{Cr}(\mathrm{VI})<\mathrm{Cd}(\mathrm{II})<\mathrm{Pb}(\mathrm{II})<\mathrm{Al}(\mathrm{III})$. HS toxicity in rats via oral administration indicated that humic substances are not toxic up to a concentration of $512 \mathrm{mg} \mathrm{kg}^{-1}$.

The complexation study of humic substances enriched with major essential metals by potentially toxic metals demonstrated that, in this competition, the essential metals are released, suggesting that the $\mathrm{HS}-\mathrm{Al}$ and $\mathrm{HS}-\mathrm{Pb}$ complexes are more stable than HS-Ca and HS-Mg. Also the competition study between humic substances and amino acids for metallic species revealed the high selectivity and affinity of humic substances for potentially toxic metals.

Pursuant to complementary studies, humic substances could be proven an interesting alternative use, for instance, in cases of acute $\mathrm{Al}(\mathrm{III})$ or $\mathrm{Pb}$ (II) poisoning, complexing with these metals and allowing their removal from the organism. Therapeutic application of humic substances is even more attractive for their low cost, widely available and easily obtainable as a natural product.

\section{Acknowledgments}

The authors are indebted to Ladislau Martin Neto of Embrapa for his assistance in this research work. This research was funded by the Brazilian Research Agencies FAPESPFundação de Amparo à Pesquisa do Estado de São Paulo and CNPq-Conselho Nacional de Desenvolvimento Científico e Tecnológico.

\section{References}

1. Carvalho, F. M.; Neto, A. M.; Tavares, T. M.; Costa,A. C. A.; Chaves, C. R.; Nascimento, L. N.; Reis, M. A.; Pan Am. J. Public Health 2003, 13, 19.

2. Hay, E.; Derazon, H.; Eisenberg, Y.; Natalia, B.; J. Emerg. Medic. 2000, 19, 159.

3. Pecze L.; Papp A.; Nagymajtenyi L.; Environ. Toxic. Pharm. 2005, 19, 775.

4. Andersen, O.; Mini-Rev. Med. Chem. 2004, 4, 11. 
5. Nastos, V.; Garagounis, M.; Abstracts of the Moortherapie 2000-Peat Therapy on it's Way Into the Next Millenium, Bad Kissinger: Germany, 2000.

6. Klaassen, C. D. In The Pharmacological Basis of Therapeutics; Hardman, J. G.; Limbird, L. E.; Molinoff, P. B.; Ruddon, R. W.; Gilman, A. G., eds. McGraw- Hill: New York, 1996, 1649.

7. Herzig, I.; Hampl, J.; Docekalova, H.; Pisarikova, B.; Vlcek, J.; Veter. Med. 1994, 39, 175.

8. Cromarty, A. D.; Rensburg, C. E. J.; Abstracts of the $12^{\text {th }}$ International Meeting International Humic Substances Society, São Pedro, Brazil, 2004.

9. Flaten, A.; Brain Res. Bull. 2001, 55, 187.

10. Yase, Y.; Yoshida, S.; Kihina, T.; Neuropath. 2001, 21, 105.

11. Rosa, A. H.; Oliveira, L. C.; Bellin, I. C.; Rocha, J. C.; Romão, L. P. C.; Filho, N. L. D.; Thermochim. Acta 2005, 433, 81.

12. Singer, L S. J.; Appl. Phys 1959, 30, 1463.

13. Weil, J. A.; Bolton, J. R.; Electron Paramagnetic Resonance: Elementary Theory and Practical Applications, $1^{\text {th }}$ ed., Wiley: New York, 1994.

14. Burba, P.; Shkinev, V.; Spivakov, B. Y.; Fresenius J. Anal. Chem. 1995, 351, 74.

15. Thompson, W. R.; Weil, C .S.; Biometric, 1952, 8, 51.

16. Rocha, J. C.; Rosa, A. H.; Furlan, M.; J. Braz. Chem. Soc. 1998, $9,51$.

17. Steelink, C. In Humic Substanes in Soil, Sediment and Water. Geochemistry, Isolation and Characterization; Aiken, G. R.; Mcknight, M. D.; Wershaw, R. L.; Maccarthy, P. eds; John Wiley \& Sons: New York, 1985.

18. Traina, S. J.; Novak, J.; Smeck, N. E.; J. Environ. Qual. P. 1990, 19, 151.

19. Li, L.; Huang, W.; Peng, P.; Sheng, G.; Fu, J.; Soil Science Society of America Journal, 2003, 67, 740.
20. Guignard, G.; Lemmé, L.; Amblés, A.; Agronomie 2000, 20, 465.

21. Rosa, A. H.; Rocha, J. C.; Furlan, M.; Quim. Nova 2000, 23, 472.

22. Rocha, J. C.; Rosa, A. H.; Substâncias Húmicas Aquáticas: Interações com Espécies Metálicas, $1^{\text {th }}$ ed., Editora UNESP: São Paulo, 2003.

23. Dick, D. P.; Mangrich, A. S.; Menezes, S. M. C.; Pereira, B. F.; J. Braz. Chem. Soc. 2002, 13, 177.

24. Ibarra, J. V.; Juan, R.; Fuel 1985, 64, 650.

25. Leinweber, P.; Schulten, H. R.; Thermochim. Acta 1992, 200, 151.

26. Sheppard, J. D.; Forgeron, D.W.; Fuel 1987, 66, 232.

27. Hayes, M. H. B. In Humic Substances: Structures, Properties and Uses; Davies, G.; Ghabbour, E. A., eds.; MPG Books: Cornwall, 1998.

28. Martin-Neto, L.; Rosell, R.; Sposito, G.; Geoderma 1998, 81, 305.

29. Florence, T. M.; Morrison, G. M.; Stauber, J. L.; Sci. Total Environ. 1992,125, 1.

30. Einax, J.; Kunze, C.; Fresenius J. Anal. Chem. 2001, 371, 660.

31. Neubecker, T. A.; Allen, H. E.; Water Res. 1983, 17, 1.

32. Town, R. M.; Powell, H. K. J.; Anal. Chim. Acta 1992, 256, 81.

33. Pearson, R. G.; J. Am. Chem. Soc. 1963, 85, 3533.

34. Santos, A.; Bellin, I. C.; Corbi, P. P.; Cuin, A.; Rosa, A. H.; Rezende, M. O. O.; Rocha, J. C.; Melnikov, P.; J. Braz. Chem. Soc. 2004, 15, 437.

Received: May 4, 2006

Web Release Date: July 17, 2007

FAPESP helped in meeting the publication costs of this article. 